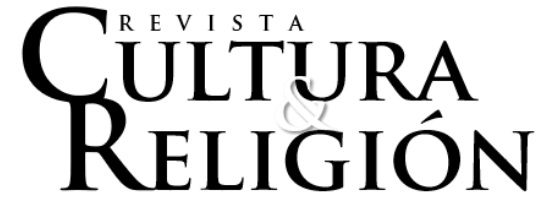

Vol. XV, $N^{\circ} 2$ (2021) pp. 39-66

Recibido: 20 de julio de 2020

Aceptado: 30 de julio de 2021

\title{
MILAGROS E INTERVENCIONES DIVINAS EN LA POESÍA ÉPICA SOBRE LA GUERRA DE ARAUCO EN EL SIGLO XVI
}

Miracles and divine interventions in epic poetry about the Arauco war in the sixteenth century

\author{
María Gabriela Huidobro Salazar* \\ Universidad Andrés Bello, Chile \\ ORCID: 0000-0001-9980-6175
}

\section{Resumen}

El presente artículo analiza los pasajes de los poemas épicos sobre la guerra de Arauco en el siglo XVI que se centran en la descripción de milagros o de intervenciones divinas -católicas o paganas-, a partir de los cuales se interpreta parte del acontecer de dicho conflicto. Desde una perspectiva histórico cultural, se hace una revisión que propone un análisis intertextual e interpretativo, que busca comprender dichos pasajes como tópicos que permitieron a los autores ofrecer una representación valorativa de la guerra, según el contexto histórico y sus particulares experiencias y miradas sobre el conflicto. Para ello, el análisis distingue dos momentos de producción de estos poemas, cuyo carácter incidió en el rol discursivo que los milagros e intervenciones divinas adquirieron para la narración de esta guerra.

Palabras clave: poesía épica, guerra de Arauco, milagros, intervenciones divinas, siglo XVI.

\footnotetext{
* Doctora en Historia, Pontificia Universidad Católica de Chile. Profesora de Historia, Licenciada en Humanidades, mención Historia, Universidad Adolfo Ibáñez. Decana de la Facultad de Educación y Ciencias Sociales, Universidad Andrés Bello. Correo electrónico: mhuidobro@unab.cl
} 


\begin{abstract}
The article analyzes the passages of the epic poems about the war of Arauco in the 16th century that focus on the description of miracles or divine interventions - Catholic or pagan - from which is interpreted part of the events of the conflict. The review is made from a cultural historical perspective, and an intertextual and interpretive analysis, which seeks to understand these passages as topics that allowed the authors to offer a value representation of the war, according to the historical context and their particular experiences on the conflict. For this, the analysis distinguishes two moments of production of these poems, whose character influenced the discursive role that miracles and divine interventions acquired for the narration of this war.
\end{abstract}

Keywords: epic poetry, Arauco War, miracles, divine interventios, sixteenth century.

\title{
Introducción
}

Desde los primeros testimonios escritos que relataron la conquista española de Chile y, en particular, la guerra de Arauco entre hispanos y mapuche, los pasajes que describieron intervenciones de naturaleza divina sobre las acciones humanas fueron recurrentes. Tanto las crónicas como los poemas épicos que versaron sobre dicho conflicto dieron lugar a la narración de episodios sobrenaturales. No obstante, aun cuando podría reconocerse como un tópico común entre ambos géneros, la formulación de estos pasajes fue distinta en cada caso y sus particularidades deben comprenderse en relación con la naturaleza de cada uno, así como con las intenciones que inspiraban a sus respectivos autores.

En el caso de las crónicas, primaron aquellos fragmentos que hablaban de la participación de María y del apóstol Santiago en favor de la empresa española, tal como ocurrió en diversas latitudes de América. En particular, el

Huidobro, M. (2021). Milagros e intervenciones divinas en la poesía épica sobre la guerra de Arauco en el siglo XVI. Revista Cultura y Religión, 15(2), 39-66. 
apóstol Santiago constituyó un símbolo discursivo importante en la conquista del Nuevo Mundo, representativo de la continuación de la lucha religiosa hispana en Europa extrapolada a suelo americano (Sanfuentes, 2008, p. 50). Su figura formó parte relevante entre las representaciones literarias y artísticas que irradiaron el Nuevo Mundo con un discurso evangelizador (Chávez, 2012, p. 147).

En Chile, los testimonios más representativos son aquellos que ofrecieron Jerónimo de Vivar ${ }^{1}$, Alonso de Góngora Marmolejo² y Pedro Mariño de Lobera ${ }^{3}$ en el siglo XVI. Los tres autores dedicaron extensos pasajes al relato de milagros protagonizados por los santos para lograr algunas extraordinarias victorias de los españoles sobre sus enemigos indígenas, respetando una estructura tipo y una argumentación común, que hicieron de estos pasajes un tópico propio de la crónica indiana.

Pese a que los autores declaraban su intención de escribir historia y de relatar verazmente los hechos de los que fueron testigos, sus obras constituyen una representación y testimonio de sus valores, principios, cosmovisión e intereses, tal como ha planteado Donoso (2008). Los pasajes alusivos a las intervenciones divinas en las crónicas deben ser abordados como relatos escritos por cristianos, conquistadores que creían o abogaban por el sentido evangélico y misional de su empresa. En este marco, las apariciones del apóstol Santiago y de la Virgen María no eran casuales. Estas constituían recursos discursivos e ideológicos de la literatura e historiografía de conquista que

\footnotetext{
${ }^{1}$ En su Crónica y relación copiosa y verdadera de los reinos de Chile (1558), Vivar describió el triunfo de un pequeño ejército español comandado por Pedro de Valdivia en Andalién contra sesenta mil araucanos. Los prisioneros habrían declarado tras la batalla que su derrota se había debido a la intervención de una mujer y de un hombre de barba blanca sobre un caballo, que habían descendido del cielo, encegueciendo a los indígenas con destellos de luz (XCVII).

${ }^{2}$ En su Historia de Chile desde su descubrimiento hasta el año de 1575 (1575), Góngora Marmolejo relata la victoria española que permitió fundar la ciudad de Concepción: quince mil enemigos habrían huido al atemorizarse por la presencia de una mujer extraordinaria y de un hombre sobre un caballo blanco (XI).

${ }^{3}$ La Crónica del Reino de Chile (1595) de Mariño de Lobera daba cuenta de las intervenciones del apóstol Santiago y de María en la defensa de la ciudad de Santiago, encegueciendo a cientos de indígenas con tierra que arrojaban a sus ojos (II, 15-16).
}

Huidobro, M. (2021). Milagros e intervenciones divinas en la poesía épica sobre la guerra de Arauco en el siglo XVI. Revista Cultura y Religión, 15(2), 39-66. 
reflejan la devoción profesada por algunos conquistadores, quienes contaban con el apoyo de su divinidad para el éxito de sus acciones (Donoso, 2008, p. 50). El fenómeno recurrente de las apariciones de María se habría facilitado por el antecedente de su asunción como propiedad distintiva de su vida, al haber llevado su cuerpo al Cielo, de acuerdo a la creencia católica, de manera íntegra e incorruptible (Fogelman, 2014, p. 218).

Las crónicas y los relatos de conquista formaron parte esencial del discurso de legitimación de la misión española en América, en oposición al mundo indígena, cuya religión podía identificarse paralelamente con la adoración a Satanás (Weckmann, 1984, p. 221). La acción de la letra fue fundamental para fortalecer y complementar la acción evangelizadora en sí misma por medio de la implantación de la "doctrina", que disponía entre los indígenas la imposición del culto católico en detrimento de las creencias en sus propias deidades (Glave y Díaz, 2020, p. 80). La escritura se hallaba al servicio de la acción española, orientada a la construcción de relatos que glorificaban los acontecimientos de colonización. La letra misma, ausente en sus formas alfabéticas dentro del mundo americano, habría permitido a los españoles confiar en su superioridad cultural, al tiempo que otorgaba a la percepción de su realidad, la validez y fiabilidad históricas que las crónicas pretendían arrogarse en razón de su valor testimonial (Martínez, 2000, pp. 34-38; Mignolo, 1992, p. 107).

Sin embargo, en los poemas épicos sobre la guerra de Arauco que datan del mismo período, los pasajes que relataron la participación de una divinidad no mantuvieron siempre las mismas temáticas ni la unidad discursiva y narrativa que, en cambio, presentaba el tópico en las crónicas. Dichas epopeyas estuvieron encabezadas por La Araucana de Alonso de Ercilla (1569-1589), cuya narración se iniciaba con los primeros años de la presencia española en Chile, para centrarse luego en la llegada del gobernador García Hurtado de Mendoza, hacia 1556, tras la muerte de Pedro de Valdivia. La obra de Ercilla fue luego continuada por Pedro de Oña con Arauco domado (1596), quien cantó

Huidobro, M. (2021). Milagros e intervenciones divinas en la poesía épica sobre la guerra de Arauco en el siglo XVI. Revista Cultura y Religión, 15(2), 39-66. 
también la empresa del mismo gobernador, exaltando su figura. Finalmente, dos poemas épicos narraron el estado crítico de la colonización española en el sur de Chile tras la muerte del gobernador Martín García Oñez de Loyola, en el episodio conocido como el Desastre de Curalaba de 1598: Purén indómito de Diego Arias de Saavedra (1603) y La guerra de Chile, obra anónima (1610).

Distanciados al menos por treinta años, los dos contextos históricos que fueron materia de estos poemas se diferenciaban por la mirada que inspiró sus respectivas representaciones sobre la guerra de Arauco. Las primeras obras versaron sobre un proceso de carácter fundacional, que iniciaba el conflicto contra los mapuche; las últimas trataron sobre una guerra que se había extendido y desgastado, agravando el padecimiento de ambas partes (Huidobro, 2017, pp. 338-339).

Más allá de tal distinción, los cuatro poemas épicos incorporaron pasajes que relatan la intervención de seres sobrenaturales, principal, aunque no exclusivamente, de figuras cristianas. Sin embargo, a diferencia de la crónica, ellas no fueron siempre mencionadas explícitamente. Su identidad se sugería, en ocasiones, mediante una presentación que atendía a la grandeza de su imagen o de sus acciones, no a su nombre, y tal como su intervención podía repercutir en el acontecer de la guerra de Arauco, así también era posible que otras figuras, tanto de la mitología grecorromana como indígena americana, participaran del argumento de estos poemas. ¿Cómo comprender esta variación? ¿No contradecirían tales personajes la mirada cristiana del discurso épico?

El tópico de las intervenciones milagrosas en los poemas épicos desarrolló ciertas particularidades que deben comprenderse a la luz de la tradición del género literario al que ellos se adscribían -fundamentalmente, de la tradición épica clásica- y del imaginario cristiano que inspiraba su visión de mundo.

Algunas investigaciones han abordado estos casos de manera monográfica, primando un enfoque crítico literario. Son los casos de Prieto

Huidobro, M. (2021). Milagros e intervenciones divinas en la poesía épica sobre la guerra de Arauco en el siglo XVI. Revista Cultura y Religión, 15(2), 39-66. 
(2001) y su análisis del milagro relatado por Ercilla en el canto IX de $L a$ Araucana de Ercilla; Faúndez (2018) y su estudio sobre el Canto II de Arauco domado de Oña; y Mata (2015), quien aborda los cantos X y XI de Las Guerras de Chile. Atendiendo a dichos estudios y considerando las observaciones expuestas, el propósito del presente artículo es alcanzar una mirada analítica de conjunto sobre lo que puede considerarse el corpus épico sobre la guerra de Arauco. El objetivo consiste en comprender en dicho corpus, desde una perspectiva histórico cultural, los pasajes épicos que dieron cabida a la intervención de divinidades en la guerra de Arauco e interpretar su sentido discursivo, identificando sus particularidades y diferencias en relación con las influencias culturales y religiosas mencionadas.

Para ello, abordaremos estas obras a partir de un análisis intertextual y de un enfoque interpretativo histórico, que comprenda el lugar y rol del tópico poético de las intervenciones divinas, en el marco discursivo de cada poema, de acuerdo con la mirada valorativa que desarrolló cada autor sobre la guerra de Arauco.

Metodológicamente, distinguiremos los poemas épicos de acuerdo con sus momentos de producción, comenzando por analizar los poemas más tempranos, escritos por Ercilla y Oña en el contexto de la gobernación de García Hurtado de Mendoza, que abrieron espacio a la participación de figuras paganas. La mención de tales figuras fue disminuyendo con el tiempo, para hacerse fuerte, en cambio, el relato de los milagros cristianos a fines del siglo $\mathrm{XVI}$, con los poemas que narraron el asedio indígena tras el desastre de Curalaba, que revisaremos a continuación. Así, será posible comprender el lugar de los milagros e intervenciones divinas en el contexto histórico que inspiró a cada poeta, y que permiten valorar el peso de la tradición católica y del bagaje cultural clásico en el proceso de conquista y colonización de Chile a lo largo de sus primeras décadas.

Huidobro, M. (2021). Milagros e intervenciones divinas en la poesía épica sobre la guerra de Arauco en el siglo XVI. Revista Cultura y Religión, 15(2), 39-66. 


\section{Fuerzas paganas y protección cristiana: La Araucana y Arauco domado}

La participación de dioses y personajes mitológicos en la poesía épica se remonta a las primeras obras del género, en las que dicha intervención parecía casi tan recurrente como la de los mismos héroes y guerreros. Basta con pensar en las epopeyas de Homero y de Virgilio, y en la participación de Afrodita, Hermes, Júpiter o Neptuno en la guerra de Troya o en la conquista de Italia. Se trataba de una acción que iba más allá de la mera presencia y que constituía una directa intervención de las divinidades en los hechos relatados. En obras como la Ilíada y la Odisea de Homero, los dioses formaban parte del desarrollo de la acción, inmiscuidos e involucrados en ella tanto como los mismos protagonistas humanos. Dicha tendencia fue consolidada luego por Virgilio, autor de la Eneida, quien sistematizó este recurso como un elemento estructural básico del género, conocido como máquina sobrenatural (Bettin, 2006, p. 627; Piñero Ramírez, 1984, p. 175).

Los ejemplos de intervención divina son innumerables y claves para la lectura de las epopeyas recién mencionadas. Ellos son todos comprensibles y valorables desde una lectura que atienda la cosmovisión de su tiempo y la religiosidad que la inspiraba. Sus autores no se explicaban el acontecer desde su desarrollo interno o como experiencias derivadas de una conciencia y acción humanas. En la epopeya del mundo antiguo, nada se concebía como un hecho que pudiese ocurrir sin la cooperación de una fuerza divina, y eso se vio reflejado en la poesía épica (Jaeger, 2006, p. 62).

Así, aun constituyendo elementos de ficción en un relato que pretendía credibilidad, el argumento mantenía verosimilitud, pues se insertaba en un contexto cultural que admitía o creía en dichos seres mitológicos, cuyas intervenciones podían caber en los límites de lo posible y de la estructura orgánica de su existencia (Sepúlveda, 1968, p. 441).

No obstante, esto es precisamente lo que pudo generar un conflicto para los poetas épicos cristianos, quienes debían mantener las formas y figuras

Huidobro, M. (2021). Milagros e intervenciones divinas en la poesía épica sobre la guerra de Arauco en el siglo XVI. Revista Cultura y Religión, 15(2), 39-66. 
tradicionales del género épico, sin contravenir su propia fe, muy distinta a la de los antiguos politeístas.

Ercilla, por ejemplo, abre el canto IX de La Araucana reflexionando acerca de los escasos testimonios sobre milagros en su época, calificando indirectamente a las intervenciones divinas como supersticiones paganas, que habían concluido con la ley cristiana:

$$
\begin{aligned}
& \text { Si los hombres no veen milagros tantos } \\
& \text { como se vieron en la edad pasada } \\
& \text { es causa haber agora pocos santos } \\
& \text { y estar la ley cristiana autorizada. } \\
& \text { (La Araucana IX, 1, 1-4) }
\end{aligned}
$$

El tópico, por lo tanto, no podía ser objeto de una simple imitación para garantizar su continuidad en la épica moderna. Su revalidación requirió de un proceso de recepción y de apropiación del estilo y de las tendencias de la tradición del género por parte de los poetas, con el fin de mantener el modelo literario, pero respetar, a la vez, los principios religiosos y culturales del cristiano europeo.

El poeta italiano Torquato Tasso (1544-1595) fue uno de los primeros en dar solución de continuidad a este tópico en tiempos modernos, lo que pudo sentar un precedente para la adaptación del mismo tema en los demás poemas, entre ellos, los que versaron sobre Arauco. Tasso imitó el empleo de la máquina sobrenatural pagana y la cristianizó, enfrentando en forma maniquea a dos planos extraterrenales, dispuestos simétricamente: el celestial cristiano y el infernal, que mantenían una pugna paralela como réplica de aquello que estuviera sucediendo en la tierra (Sepúlveda, 1968, p. 441). Estos dos extremos permitieron a los poetas incorporar y desarrollar este tópico, sin faltar a las creencias cristianas y ajustándose, al mismo tiempo, a los criterios de verosimilitud que debían regir sobre las obras de este género.

Huidobro, M. (2021). Milagros e intervenciones divinas en la poesía épica sobre la guerra de Arauco en el siglo XVI. Revista Cultura y Religión, 15(2), 39-66. 
La solución fue continuada por los poetas de la guerra de Arauco, en especial por Pedro de Oña en Arauco domado. El pasaje que mejor desarrolló este tópico se inserta en los primeros cantos del poema. El argumento se inicia tras la muerte de Pedro de Valdivia a manos de los rebeldes araucanos, quienes comienzan a recuperar sus tierras liderados por el cacique Caupolicán. Nada sabía este último sobre los preparativos hispanos para recobrar el territorio perdido, comandados por García Hurtado de Mendoza, quien zarparía desde Perú con dirección a Concepción. Y es entonces cuando Oña inserta un extenso pasaje que ofrece un catálogo de figuras mitológicas grecorromanas, convocadas por Satanás.

El pasaje evoca el tópico épico de los concilios divinos, como los de la Ilíada (IV, 1-7 4), la Odisea (1, 26-95) y la Eneida (X, 1-117), en los que los seres sobrenaturales se reunían para analizar la situación de los hombres y determinar la causa a la que apoyarían. Así, en Arauco domado, las figuras mitológicas de los infiernos son convocados para apoyar al bando indígena, que expresamente se contraponía a la bondad de García Hurtado: ${ }^{4}$

El azufrado Rey del hondo averno

mandó juntar en lóbrego concilio

a los que le juraron domicilio

y están al disponer de su gobierno,

para que contra el justo mozo tierno

al bárbaro se dé favor y auxilio

haciendo su poder, porque le venza,

${ }^{4}$ Castro y Zapata (2009, pp. 286-287) ven en este pasaje un fuerte eco de la Eneida. En el caso de Arauco domado, el dios de los Infiernos, Plutón, se presentaría, tal como sugieren las autoras, con caracteres de demonio cristiano, pero parecería al mismo tiempo cumplir un rol como el que Juno ejercía en el poema virgiliano. Se trata de un pasaje que refleja el sincretismo cultural que aúna la tradición clásica y católica, y que puede hallarse en otros poemas de la conquista hispanoamericana, como ocurre con La Cristiada de Diego de Hojeda (Quesada, 2008, p. 262).

Huidobro, M. (2021). Milagros e intervenciones divinas en la poesía épica sobre la guerra de Arauco en el siglo XVI. Revista Cultura y Religión, 15(2), 39-66. 
y saque al orco triste de vergüenza.

(Arauco domado IV, 66)

El Cancerbero ladra, y "al son de aquella horrísona bocina” (IV, 67, 1), comienzan a desfilar las figuras infernales: Sísifo, Tántalo, Demogorgon, ${ }^{5}$ Tereo, las Bélides, las Euménides, Eaco, Minos, Radamanto y los más afamados criminales de la Antigüedad (IV, 68 y ss.). El encuentro concluye, finalmente, con el envío de la furia Megera como mensajera de Plutón para hablar con Caupolicán. Interrumpiendo un momento idílico entre el cacique y su amada Fresia, la Furia se le aparece como una teofanía, para insuflar en él el furor bélico y prepararse para rechazar al gobernador español (IV, 65 y ss.).

El pasaje se compone de algunas "escenas-tipo" propias de este tópico. La primera de ellas correspondería al concilio divino presidido por una figura paterna -en este caso Plutón-, donde se debate sobre el destino del héroe. Esta figura mayor, sin embargo, no intervendría directamente sobre el comportamiento de los personajes, sino que utilizaría un mediador, rol que en Arauco domado cumple Megera. Es ella la que personificaría el segundo tipo de escena, la teofanía, esto es, la aparición de la divinidad ante el héroe para advertirlo y motivarlo en sus deberes (Louden, 2008, p. 91).

Los clasicismos de este pasaje ofrecen un indicio respecto de los motivos y el sentido que la inclusión de divinidades paganas tendría en un poema épico cristiano. Se trata, por lo demás, de figuras específicas: seres mitológicos asociados, en su mayoría, al Hades grecolatino. Las intervenciones sobrenaturales no solo constituían un tópico literario propio del género, sino que también podían ejercer una función ideológica que fortalecía el discurso de legitimación de la conquista. Caupolicán, movido por las fuerzas sobrenaturales de un imaginario idólatra, asociadas todas al inframundo o a un plano infernal, decide rebelarse frente a la voluntad evangelizadora de los cristianos.

\footnotetext{
${ }^{5}$ Se trata de una divinidad construida por Boccaccio en el siglo XIV, en su Genealogia deorum gentilium, que podría remitir al demiurgo platónico (Solomon, 2012).

Huidobro, M. (2021). Milagros e intervenciones divinas en la poesía épica sobre la guerra de Arauco en el siglo XVI. Revista Cultura y Religión, 15(2), 39-66.
} 
La presencia poética de los seres mitológicos de Grecia y Roma en Arauco respondería a la estructura que subyace al argumento central de la obra, que distinguía en la oposición de españoles y araucanos, el contraste entre cristianismo y paganismo, civilización y barbarie, verdad y error, orden y caos. De este modo, el tópico de las intervenciones divinas reforzaba la imagen del antagonismo básico a partir del cual los poetas representaron el conflicto de la guerra de conquista. En este sentido, podría pensarse en un discurso análogo, en términos ideológicos, entre las crónicas y los poemas épicos. Sin embargo, las formas narrativas a partir de las cuales se construyen estos pasajes pueden diferir. En opinión de Donoso (2008, p. 40), si bien la intervención directa de las deidades en batalla se remonta a los relatos de la Antigüedad, la versión cristiana, tal como se presenta en las crónicas, constituiría una proyección de los pasajes medievales que insertaron este tópico bajo el influjo de la cultura islámica.

Lejos de resultar contradictorio con los criterios católicos que inspiraban estas obras, este tópico mantenía la coherencia discursiva de los relatos, sin quebrar su base histórica. Después de todo, la presencia de figuras mitológicas paganas se asociaba siempre al bando indígena. Tal como observa Louden (2008, p. 90), en la poesía épica el retrato de los dioses estaría determinado por sus relaciones con un héroe, y esto se expresa luego en el modo como se manifiestan a favor o en contra de este, bien mediante concilios divinos, teofanías o expresiones de cólera.

El testimonio de tal participación, además, era transcrito, pero no asumido por el autor, de manera tal que no debía hacerse cargo de la veracidad del pasaje. La imagen del mundo araucano era materia poemática, pues se trataba de un mundo desconocido para los lectores europeos. Así, su representación podía construirse a partir de la creatividad del poeta y de los modelos que la tradición literaria ofrecía. El universo indígena daba cabida a todos aquellos elementos que en apariencia podrían contravenir las creencias y cosmovisión del autor, aunque finalmente las reforzaban por oposición.

Huidobro, M. (2021). Milagros e intervenciones divinas en la poesía épica sobre la guerra de Arauco en el siglo XVI. Revista Cultura y Religión, 15(2), 39-66. 
Este es entonces el principio a partir del cual podemos comprender el pasaje inscrito en Arauco domado. El mismo canto IV, junto con la intervención de los seres mitológicos, narraba también la tormenta que azotó a las naves de García Hurtado de Mendoza cuando se dirigía a Chile para enfrentar a Caupolicán. Según la interpretación del poeta, la tempestad habría tenido una causa diabólica, mientras su desenlace, con la salvación de las embarcaciones, se habría debido a la voluntad de la divina Providencia.

No es fábula ni poética figura,

ficción artificiosa ni ornamento,

sino verdad patente la que cuento,

que es de lo que se precia mi escritura;

y débese entender que tal hechura

no solamente fue del mar y viento,

sino de aquel diabólico vestigio

que siempre nos persigue en este siglo.

(Arauco domado IV, 14)

La interpretación de la tempestad como obra infernal se reitera en un monólogo de Satanás, el "negro Rey del triste alojamiento" (Arauco domado IV, 80, 5), quien afirma haber sido él, el causante de la tormenta (IV, 90, 3-4). Oña ofrece una explicación de los acontecimientos asociada a sus creencias religiosas y a su cosmovisión cristiana. Este afirma que los males serían, a veces, instancias que Dios ofrecía para probar la virtud del héroe; en otras oportunidades, obstáculos diabólicos, representados por figuras mitológicas, para poner fin a las pretensiones cristianas. Por eso, los personajes que intervienen desde esta última perspectiva están siempre ligados al mundo indígena, en cuanto este pretendía impedir la conquista política y espiritual de las tierras araucanas.

Huidobro, M. (2021). Milagros e intervenciones divinas en la poesía épica sobre la guerra de Arauco en el siglo XVI. Revista Cultura y Religión, 15(2), 39-66. 
Así, pese a tratarse de un pasaje ficticio, la tempestad provocada, el concilio infernal y la aparición de Megera confieren sentido al relato histórico de la guerra de Arauco, justificando la empresa española. Esta última no consistiría meramente en una campaña de conquista, sino en una guerra que se validaba por enfrentar a un pueblo rebelde, que había traicionado la fe ofrecida desde los primeros conquistadores. Así lo hace saber constantemente el poeta, que ofrece un retrato de los araucanos como bárbaros, cuya condición tiene un sentido especialmente religioso y moral: "La sacra evangélica doctrina / sembrada en el estéril pecho bruto" (Arauco domado I, 10, 1-2).

El concilio y la teofanía insertos en la obra no deben ser, por tanto, abordados como escenas cuyo valor reside únicamente en su calidad literaria, ni cuyo sentido se resuelve en sí mismas. Se trata de pasajes que, a partir de un tópico propio de la tradición épica, fortalecen el discurso para la representación del conflicto, sin contradecir la verosimilitud de su relato. La fe cristiana de Pedro de Oña se transmitía, en este caso, por contraposición.

En La Araucana, en tanto, la garantía de verosimilitud se resuelve de manera similar, pero las intervenciones divinas incorporan además a figuras cristianas. Sin embargo, para hablar de hechos sobrenaturales, Ercilla juega retóricamente con la posibilidad de creer en milagros. Los testigos de la aparición que él relata son nuevamente indígenas, lo que permite al poeta cuidarse de la responsabilidad del testimonio y enfatizar en sus dudas frente a lo maravilloso (Prieto, 2001, p. 209).

Ercilla afirma que Dios interviene, generalmente, mediante hechos naturales, no extraordinarios, los que a simple vista no parecen ser obra suya. De ahí que, enfatizando en el criterio de verdad que pretendía para su poema, expresa sus dudas sobre insertar un relato sobrenatural (IX, 4). Junto con ello, para garantizar al mismo tiempo la posibilidad de creer en el testimonio indígena, el poeta se apoya en el crecido número de testigos que lo ratificarían y en la posibilidad de que Dios hubiera permitido que, por esa extraordinaria oportunidad, tuvieran tales visiones:

Huidobro, M. (2021). Milagros e intervenciones divinas en la poesía épica sobre la guerra de Arauco en el siglo XVI. Revista Cultura y Religión, 15(2), 39-66. 


\author{
Y manifiesto vemos hoy en día \\ que, porque la ley sacra se estendiese \\ nuestro Dios los milagros permitía \\ y que el natural orden se excediese; \\ presumirse podrá por esta vía \\ que para que a la fe se redujese \\ la bárbara costumbre y ciega gente \\ usase de milagros claramente.
}

(La Araucana IX, 5)

De esta manera, el poeta no solo mantiene cierto grado de verosimilitud en el pasaje que relataría y da continuidad al tópico propio de la épica, sino también, puede hacer uso de este para dotar de sentido a las acciones que relata.

El pasaje de La Araucana narra lo siguiente. Caupolicán y sus hombres planeaban atacar La Imperial, cuando, en medio de una súbita tormenta descrita con alusiones mitológicas (IX, 9) -, se les aparece Eponamón. En la Declaración de algunas dudas que se puede ofrecer en esta obra, que el poeta incluyó en La Araucana, Ercilla define a Eponamón como el "demonio, por el cual juran cuando quieren obligarse infaliblemente a cumplir lo que prometen" (Ercilla, [1569-1589] 2002, p. 55). Su presencia, que contrastaba con la ayuda sobrenatural de Dios, servía así para resaltar la oposición moral y religiosa entre ambos bandos. Descrito como una figura monstruosa -"en forma de un dragón horrible y fiero / con enroscada cola envuelta en fuego" (IX, 10, 6-7) -, incitaba a los araucanos a atacar. El poeta adoptaba así la mención de una entidad sobrenatural mapuche, desde la terminología local, reforzando la alteridad de ambos bandos. La religiosidad mapuche se caracterizaba por complejos imaginarios que reflejaban sus formas de comprender el mundo, integrados a su contexto social y cultural. Estos consideraban una estructura vertical del universo, que incluía un inframundo (Rodríguez y Saavedra, 2008, p. 99).

Huidobro, M. (2021). Milagros e intervenciones divinas en la poesía épica sobre la guerra de Arauco en el siglo XVI. Revista Cultura y Religión, 15(2), 39-66. 
La voluntad de llevar la guerra, de hacer daño y utilizar la violencia era obra, entonces, del demonio, cuya presencia era capaz de ensombrecer incluso el mismo paisaje. Solo su partida da fin a la tormenta, cuando "en humo se deshizo y no lo vieron" (IX, 11, 8). ${ }^{6}$

El contraste con el pasaje que sigue a continuación es radical. La segunda aparición se enmarca en una escena amena y tranquilizadora, asociada evidentemente a la bondad de la figura que se presentaría ante los araucanos. Su nombre, desconocido para los indígenas, permite reforzar la noción de alteridad de este segundo personaje. Era una figura ajena a los indígenas y, por lo tanto, propia del bando enemigo, asociado de este modo a la causa correcta.

Ercilla tampoco indica su nombre, seguramente apelando al rigor histórico que le impediría agregar más información que aquella que le habrían ofrecido los indígenas. No obstante, los detalles sugieren que se trataba de la aparición de María - “cubierta de un hermoso y limpio velo” (IX, 13, 5) - y del apóstol Santiago, pues "venía de un viejo cano acompañada, / al parecer de grave y santa vida" (IX, 14, 3-4).

$\mathrm{Su}$ presencia reconfortante, así como su mensaje, evidencian el carácter ideológico de este pasaje, en el que, tal como en Arauco domado, se avalaba y justificaba la causa imperial española en su sentido religioso. De esta manera, la intervención de María no constituye solo la imitación del tópico, sino la utilización de este en el sentido discursivo del poema:

Les dice: "¿A dónde andáis, gente perdida?

Volved, volved el paso a vuestra tierra,

No vais a la Imperial a mover guerra.

Que Dios quiere ayudar a sus cristianos

y darles sobre vos mando y potencia

\footnotetext{
${ }^{6}$ Este verso evoca, en opinión de Lerner (2002), aquel de la Eneida V, 740 -Dicerat et tenuis fugit ceu fumus in auras--, sobre la aparición de Anquises a Eneas. A ello puede agregarse una nueva alusión mitológica a los vientos, que en versos de Ercilla "se van a sus cavernas retirando" (La Araucana IX, 12, 4).

Huidobro, M. (2021). Milagros e intervenciones divinas en la poesía épica sobre la guerra de Arauco en el siglo XVI. Revista Cultura y Religión, 15(2), 39-66.
} 
pues ingratos, rebeldes, inhumanos

así le habéis negado la obediencia.

Mirad, no vais allá, porque en sus manos

pondrá Dios el cuchillo y la sentencia".

Diciendo esto y dejando el bajo suelo,

por el aire espacioso subió al cielo.

(La Araucana IX, 14, 6 y ss.)

La intervención divina surte efecto. Los araucanos vuelven sus pasos y desisten de su ataque. Sin embargo, para evitar que el pasaje pareciera simple ficción, Ercilla se encarga de fechar el acontecimiento, a 23 de abril de 1554 (IX, 18).

El tópico respeta de este modo el rasgo de verosimilitud, tal como se requería también en los poemas antiguos. La Araucana mantiene la pretensión de su autor de apegarse a la historia, pero asegura al mismo tiempo sus tonos épicos mediante la fantasía propia de la epopeya. No se trata exclusivamente de un componente fantástico, ya que su condición extraordinaria se relativiza a través de la voz indígena y del contexto histórico que envuelve el acontecimiento (Goic, 1988, p. 197). Tras el relato de lo sobrenatural descansa la dinámica básica de la guerra de Arauco que, lejos de la fantasía, oponía a las huestes infieles, representadas en la oscuridad de Eponamón, contra las fuerzas católicas, protegidas por la presencia de María y de Santiago.

La presencia de divinidades tiene lugar en poemas que se pretendían históricos, porque se adaptan al contexto de sus autores y lectores, así como a su cosmovisión cristiana. De este modo, no solo mantienen su continuidad con la tradición que los inspiraba, sino que también actualizan y dan vigencia a su sentido: el tópico literario de las intervenciones divinas, ofrecido por la tradición épica, servía a la elaboración y representación de una oposición maniquea que avalaba los ideales de conquista.

Huidobro, M. (2021). Milagros e intervenciones divinas en la poesía épica sobre la guerra de Arauco en el siglo XVI. Revista Cultura y Religión, 15(2), 39-66. 


\section{La necesidad del milagro a fines del siglo XVI: Purén indómito y La guerra de Chile}

La percepción sobre la guerra de Arauco cambió con el transcurso de los años. Hacia fines del siglo XVI, y sobre todo a partir del desastre de Curalaba, los constantes enfrentamientos, la violencia y la pérdida de vidas y de territorios para uno y otro bando generaron una mirada más crítica y trágica respecto del conflicto.

En ambos extremos, el español y el indígena, era posible advertir excesos y abusos que enrarecían el cuadro moral de la guerra de Arauco, impidiendo a sus testigos visualizar un posible y feliz desenlace para el conflicto. Así, este fue perdiendo su carácter heroico en la literatura de conquista y adquirió un tono de lamentación o, en algunos casos, incluso de denuncia (Barraza, 2004; Rodríguez, 2000; Triviños y Rodríguez, 1996, p. 42).

Esto implicó que el discurso base de los poemas también fuera objeto de una transformación, y que sus recursos narrativos debieran adaptarse al sentido que los autores buscaran conferir a la representación de los hechos relatados. Así puede percibirse en las obras Purén indómito y La guerra de Chile.

Desde la perspectiva religiosa y de los ideales originales de la conquista, los autores de ambos poemas culparon en gran parte a los mismos españoles por los males que sufrieron a partir de la muerte de Oñez de Loyola en 1598. Los abusos de los encomenderos y la violencia de los soldados habrían sido la causa de la rebelión de los indígenas, para quienes habría sido imposible adherir a una fe cristiana que no se practicaba y que parecía quedarse solo al nivel de la palabra. Se trataba de una contradicción que el poeta Diego Arias en Purén indómito denuncia a través de un monólogo del cacique Pailamacho, quien repasa los Diez Mandamientos para dar cuenta, uno a uno, del modo en que los españoles los habían transgredido (III, 28-35).

En boca de los araucanos, el poeta dirige una aguda crítica al contradictorio e impío estilo de vida de algunos conquistadores. Purén indómito

Huidobro, M. (2021). Milagros e intervenciones divinas en la poesía épica sobre la guerra de Arauco en el siglo XVI. Revista Cultura y Religión, 15(2), 39-66. 
es una obra que se estructura en base a un discurso que desarticula el enfoque épico tradicional, erosionando la mirada oficial del Imperio español, así como la fuerza de un discurso y de una verdad que, hasta entonces, proclamaban sin mayor cuestionamiento, la superioridad y legitimidad de la causa hispana en Chile. En Purén indómito, la guerra ya no se celebra, se lamenta (Barraza, 2012, p. 14; García, 1960, p. 95; Triviños y Rodríguez, 1996, p. 45).

En la misma línea discursiva, otro pasaje del mismo poema realiza una crítica a los colonos de la ciudad de Valdivia (XVIII). Este describe la visión que un anciano español habría tenido, y en la que se le había aparecido un ángel "airado por el vicio" (XVIII, 37, 5) de los pobladores, pretendiendo incendiar la ciudad con una antorcha. Al día siguiente, al relatar el anciano su visión a los vecinos, el público lo habría desoído, precisamente por la incredulidad y la ceguera que su propio pecado les provocaba.

La causa de la crisis del proceso de conquista y colonización de Chile habría sido, según la visión que se desprende del poema, la inconsecuencia entre los ideales del Imperio español y el proceder concreto de sus hombres. De este modo, el tópico de las intervenciones sobrenaturales en Purén indómito y en La guerra de Chile no podía responder, como en los anteriores, al esfuerzo escrito por dar legitimación a los hechos de la conquista, sino más bien a la pretensión de recobrar los ideales misionales olvidados y el heroísmo que correspondía a un poema épico.

Todos los pasajes que incorporan la temática de las intervenciones divinas son relatados en circunstancias y formas similares. El motivo para introducirlos consiste en la descripción del sitio de un fuerte o ciudad española, cuyos habitantes sufren hambre y sed tras días o meses de asedio. Este fue un argumento recurrente en ambos poemas, pues constituyó un eje central del proceso de guerra a fines del siglo XVI.

Las circunstancias de estos asedios, con el sufrimiento, violencia y tragedia que ellos supusieron para los colonos y soldados hispanos, marcaron a sus protagonistas, por lo que no solo fueron atestiguados en estos poemas, sino

Huidobro, M. (2021). Milagros e intervenciones divinas en la poesía épica sobre la guerra de Arauco en el siglo XVI. Revista Cultura y Religión, 15(2), 39-66. 
que también formaron parte del testimonio de crónicas como las de Diego de Rosales (V, 10-12) y Alonso de Ovalle (VI, 15-16). Los cronistas, sin embargo, suelen alabar el valor y la tenacidad con la que los españoles resistían, prácticamente hasta morir, el ataque indígena, afirmando que los episodios acababan con la rendición, con el socorro de otras ciudades, o bien, con el arrojo de algunos habitantes dispuestos a enfrentar a sus enemigos.

En la épica, en cambio, estas circunstancias, en especial cuando concluyen con desenlaces inesperados, son las que precisamente se prestan para inspirar reflexiones o explicaciones alusivas a un milagro o a una solución extraordinaria.

La estructura narrativa es siempre la misma. Los poetas inician estos pasajes destacando, en primer lugar, la manifiesta desventaja en la que se encontraban los conquistadores o ciudadanos frente a sus enemigos indígenas o ante la adversidad de la naturaleza. La presentación se sigue de la descripción de los padecimientos que el asedio suponía, sobre todo el hambre y la sed, y de la impotencia de las víctimas para hacer frente a una situación que no parecía tener soluciones posibles. Así, el desenlace surge de un "imposible", de un hecho inexplicable desde la lógica racional o desde el orden natural. En otras palabras, su salvación llega por un milagro, cuya posibilidad solo puede avalarse desde la fe del autor y de sus lectores (Castañeda, 2004, p. 133).

En términos literarios, se recurre a la clásica fórmula deus ex machina, estrategia originalmente utilizada en el teatro griego antiguo, que consiste en la irrupción inesperada de la divinidad para dar solución a un problema (Johnston, 2016).

Purén indómito (XI, 70-82; XIII, 6-7; XXII, 61-70) y La guerra de Chile (X, 83-102) dieron amplia cabida a este recurso. La desesperación de los españoles ante el asedio, la amenaza y el abandono, los lleva a reunirse en alguna capilla o a sacar en procesión la imagen de la Virgen María, para rogarle el perdón de sus pecados y solicitar su intervención en auxilio de la ciudad. La

Huidobro, M. (2021). Milagros e intervenciones divinas en la poesía épica sobre la guerra de Arauco en el siglo XVI. Revista Cultura y Religión, 15(2), 39-66. 
representación de estos momentos los carga de dramatismo, resaltando el arrepentimiento de unos o la inquebrantable fe de otros.

Luego, ante las súplicas y oraciones, los pasajes se siguen de la misma resolución y desenlace: el cielo se oscurece, relámpagos y truenos anuncian una tempestad y la lluvia cae copiosamente sobre la ciudad o el fuerte. Y no se trata de un simple aguacero. La tormenta puede inundar los alrededores y amenazar la vida de quienes se quedan allí. Así, mientras los españoles, refugiados en sus casas, acuden a llenar sus cántaros con agua, agradeciendo el milagro que renueva sus energías, los indígenas huyen atemorizados para protegerse de la tempestad.

En Purén indómito, la ciudad de La Imperial pasa tres veces por una situación similar, y cada una de ellas se resuelve por un milagro que se explica mediante la reconversión de los españoles. Dios, dice el poeta, había escuchado sus ruegos y auxilia a quienes, pese a haberlo olvidado en algún momento, se hallaban en Chile para defender su causa y expandir su fe:

Es el manjar de Dios los corazones

de los que se los dan con pecho blando,

en cuyas voluntades reconoce

al que su santo espíritu conoce.

(Purén indómito XXIII, 62, 5-8)

Por su parte, el autor de La guerra de Chile ofrece un pasaje que, tal vez, sea el que mejor apela a esa oposición que se sentía perdida entre la justicia y la bondad de la causa española, y el error y el pecado del bando indígena. En el canto $\mathrm{X}$, el poeta presenta primero a Pangalino, un mago indígena que realiza un conjuro para enfurecer al clima, con el fin de provocar una sequía que favoreciese a su bando y debilitase a los asediados españoles (X, 29-60). Su invocación surte efecto, abriéndose así el episodio de lo sobrenatural vinculado, inicialmente, a la magia idólatra. Atemorizados en dichas circunstancias, los españoles optan, entonces, por elevar sus oraciones a María. Así, logran que

Huidobro, M. (2021). Milagros e intervenciones divinas en la poesía épica sobre la guerra de Arauco en el siglo XVI. Revista Cultura y Religión, 15(2), 39-66. 
vuelva a llover, con tal intensidad que, por otra parte, acaban anegándose los campamentos enemigos (X, 61-100). El pasaje se establece sobre la base de una contraposición entre lo pagano y lo cristiano; ambas fuerzas se enfrentan, conflicto que finaliza con la victoria de la fe y del milagro católico. El credo español logra vencer a la superstición indígena.

Las críticas a la acción hispana en estos poemas no consisten, por tanto, en reparos frente a la causa conquistadora en sí. Los autores manifiestan su percepción respecto de una dicotomía entre los ideales que debían inspirar el proceso y la realidad histórica que no los correspondía. Así, la crítica al actuar hispano no implica una oposición al hecho de conquista y de colonización de las tierras y pueblos de Chile.

Los milagros marianos y divinos presentes en Purén indómito y $L a$ guerra de Chile mantuvieron, de esta manera, una continuidad de estilo con los modelos épicos clásicos y con el ejemplo de La Araucana y Arauco domado. Sin embargo, al mismo tiempo, resignificaron su sentido, pues difícilmente habrían podido concebir la participación divina en los términos de Ercilla y de Oña, en la medida en que se veían obligados a cuestionar la moralidad de los hechos, tal como el veredicto de la historia se los presentaba. Diego Arias y el poeta de La guerra de Chile ofrecen la imagen de un mundo escindido y trágico, frente al cual pretendían provocar una reacción crítica.

Desde esta perspectiva, la poesía de Arias de Saavedra, así como La guerra de Chile, parecen haber encaminado la tradición literaria inaugurada por Ercilla hacia un período "tardío". Se trata de una poesía destinada a conmover y advertir. Su visión de la guerra resulta más realista y cruda. La valentía de los personajes se diluye en los sufrimientos y en la humanidad de los mismos, imposibilitando al lector seguir admirándose de una multiplicidad de gestas, que escaseaban para entonces. Antes que héroes, en los poemas tardíos parecen dominar los antihéroes, cuyo modelo debía evitarse a favor de la salvación de la causa imperial y colonizadora. Esta última se buscaba, pero se mantenía al nivel de un ideal, alejada del quehacer cotidiano de la guerra.

Huidobro, M. (2021). Milagros e intervenciones divinas en la poesía épica sobre la guerra de Arauco en el siglo XVI. Revista Cultura y Religión, 15(2), 39-66. 
Ambos poemas continuaron así la tradición de la epopeya histórica, pero ofrecieron un nuevo tono para el ciclo épico que había comenzado $L a$ Araucana. En estas últimas obras es posible reconocer el asomo de un estilo barroco, que exaltó sobre la guerra, elementos como la crueldad y la emocionalidad, dando nueva fuerza a representaciones tardomedievales como el asombro, la religiosidad y lo maravilloso. Este carácter repercutió, además, en una subordinación de los elementos mitológicos paganos, indígenas y clásicos, a la temática religiosa estrictamente cristiana, con un tono verosímil, casi realista, que restringe los elementos mágicos, pero no los religiosos (García, 1960).

De esta manera, en ambos poemas, cuyos autores, paradójicamente, parecen haber tenido un mejor sentido de la historicidad y una mayor necesidad de realizar un relato objetivo y verosímil para expresar sus críticas, el tópico de las intervenciones divinas y de los milagros fue más frecuente. El tópico literario se puso al servicio de las necesidades y preocupaciones de los poetas. Por esta razón, si la perspectiva con la que se abordaba la moralidad de la guerra había cambiado, también debió variar la percepción sobre sus implicancias religiosas.

Si bien Arauco no debió percibirse ya como la tierra de héroes de $L a$ Araucana o de Arauco domado, lo épico debía pervivir, al menos como un referente moral. Ante la ausencia de individuos o acciones dignos de admirar, la poética de lo maravilloso permitió suplir la carencia de lo heroico, evocando aquellos ideales que debían constituir, de todos modos, un referente para la conquista.

\section{Conclusiones}

Si bien el tópico de las intervenciones divinas y sobrenaturales en la guerra de Arauco fue un motivo frecuente en la literatura española cristiana sobre la conquista de Chile, su formulación fue objeto de variaciones en los

Huidobro, M. (2021). Milagros e intervenciones divinas en la poesía épica sobre la guerra de Arauco en el siglo XVI. Revista Cultura y Religión, 15(2), 39-66. 
diversos géneros y obras que le dieron cabida. La valoración de estos relatos debe considerar siempre el momento histórico que influyó sobre las vivencias e imaginarios de cada autor.

Las crónicas de Mariño de Lobera, Góngora Marmolejo y Vivar abordaron principalmente el período inicial de la presencia española en Chile, concentrándose en los hechos protagonizados por Pedro de Valdivia, Francisco de Villagra y Gerónimo de Alderete. Se trataba de una etapa de descubrimiento y avanzada de las huestes hispanas, para quienes las tierras y pueblos del sur se concebían distantes, ajenos y desafiantes. El tono de la aventura y de la acción heroica, por tanto, primó en las crónicas de dichos autores, dando cabida a una formulación coherente de los relatos sobre apariciones de María y de Santiago al rescate de los conquistadores y de la empresa cristiana.

Los ecos de tal formulación pueden percibirse también en los poemas épicos sobre la guerra de Arauco, aun cuando su estructura cambiara conforme a las propiedades del género y al contexto histórico que inspiró a sus autores. Tanto La Araucana como Arauco domado, los dos poemas más clásicos del corpus épico sobre la conquista de Chile, reformularon el tópico incorporando además la participación de seres mitológicos al argumento de sus obras, tal como dictaba el canon literario del género.

Aun cuando ello pareciera contradictorio a la fe de los poetas, el recurso fortalecía el discurso cristiano subyacente al relato. Al insertarse el elemento de lo sobrenatural y los episodios alusivos a milagros, el enfrentamiento de españoles e indígenas dejaba de ser solo una guerra movida por intereses terrenales. Antes bien, pasaba a tratarse de un conflicto trascendente, de significación religiosa, simbolizada en la antinomia de las divinidades paganas y de Dios cristiano, que elevaba y legitimaba la causa conquistadora. La Araucana y Arauco domado mantuvieron así el estilo clásico de la poesía épica que se arrastraba desde una larga tradición literaria, adaptando al mismo tiempo sus tópicos y recursos a las necesidades de un imaginario y universo católicos.

Huidobro, M. (2021). Milagros e intervenciones divinas en la poesía épica sobre la guerra de Arauco en el siglo XVI. Revista Cultura y Religión, 15(2), 39-66. 
Sin embargo, el periodo que transcurrió entre el momento histórico que inspiró los poemas de Alonso de Ercilla y Pedro de Oña, en tiempos de García Hurtado, y aquel que impactó a Diego Arias y al autor de La guerra de Chile, generó un profundo cambio en la percepción de los escritores españoles sobre el proceso de conquista del sur de Chile. Para fines del siglo XVI, el desgaste de la guerra corrompió el cuadro moral que definía la escritura y narración de sus acontecimientos. Por eso, el argumento de la religiosidad y la fe en los milagros también asumió un rol diferente en dichos poemas. Tal como el discurso de los poemas tardíos, el lugar de las intervenciones divinas, en este marco, fue objeto de una reformulación, llevando a un uso más explícito y frecuente de este recurso.

En la necesidad de rescatar elementos dignos de admiración para una epopeya y de apelar a los ideales que debían inspirar la conquista de Chile, pudo haber radicado la importancia de describir milagros e intervenciones sobrenaturales como un fenómeno propio de la guerra de Arauco. Ellos constituyeron no solo el elemento divino que otorgaba el tono de lo maravilloso y admirable a las obras épicas, sino que también contribuyeron a asegurar un discurso moral e ideológico que, ante los hechos, parecía debilitado.

Los auxilios de María a los asediados conquistadores confirmaban que España seguía siendo el bando de Dios, pero exigían al mismo tiempo el correcto actuar de sus integrantes. Las intervenciones sobrenaturales, como tópico proveniente de la poesía épica clásica, cumplieron así con un rol que no solo puede abordarse en función de la continuidad de una tradición literaria, sino que también debe comprenderse como un recurso que permitió a los poetas, dotar y ampliar el sentido de las acciones que cantaban, tal como se proyectará hacia el siglo XVII en los nuevos relatos sobre la conquista.

La religiosidad inscrita en los poemas sobre la Guerra de Arauco no cumplía solo con meros formulismos o protocolos estilísticos. Ella contenía y representaba la visión de cada poeta sobre sus propias vivencias y sobre la

Huidobro, M. (2021). Milagros e intervenciones divinas en la poesía épica sobre la guerra de Arauco en el siglo XVI. Revista Cultura y Religión, 15(2), 39-66. 
historia que relató, facilitando así la comprensión y significación de una historia cristiana de la conquista para su exaltación y legitimidad.

\section{Referencias bibliográficas}

Anónimo. ([1610] 1996). La guerra de Chile. Santiago: Universidad de Chile. Arias de Saavedra, Diego. (ed. 1984). Purén indómito. Santiago, Chile: Biblioteca Nacional.

Barraza, E. (2004). De La Araucana a Butamalón. El discurso de la conquista y el canon de la literatura chilena. Valdivia: Andros-Anejo 17.

Barraza, E. (2012). Sobre la (no) clausura de La Araucana. Alpha, (34), 9-24.

Bettin, G. (2006). Per un repertorio dei temi e delle convenzioni del poema épico e caballeresco: 1520-1580. Venezia: Instituto Veneto di Scienze, Lettere ed Arti.

Castañeda, F. (2004). Los milagros y la guerra justa en la conquista del Nuevo Mundo. En D. Bonnett y F. Castañeda (eds.), El Nuevo Mundo. Problemas y debates (pp. 126-134). Bogotá: Universidad de Los Andes.

Castro, M. D. y Zapata, A. (2009). Tópicos épicos de cuño virgiliano en el "Arauco domado" de Pedro de Oña. En T. Arcos, J. Fernández y F. Moya del Baño (coords.), Pectora mulcet: estudios de retórica y oratoria latinas (pp. 277-289). Logroño: Instituto de Estudios Riojanos.

Chávez, L. (2012). La utopía del Perfecto Christiano en la literatura sacra posttridentina. Senderos terrenales para tocar el cielo colonial del siglo XVII. Revista Cultura\&Religión, 6(1), 145-163.

Donoso, M. (2008). Sobre la presencia de elementos sobrenaturales en dos crónicas chilenas del siglo XVI. Anales de Literatura Chilena, 9(10), 37-51.

Ercilla, A. de ([1569-1589] 2002). La Araucana. Madrid: Cátedra.

Faúndez, R. (2018). Ingenio etnográfico y tradición poética en el Canto II de Arauco domado de Pedro de Oña (1596). Hipogrifo, 6(1), 587-602.

Huidobro, M. (2021). Milagros e intervenciones divinas en la poesía épica sobre la guerra de Arauco en el siglo XVI. Revista Cultura y Religión, 15(2), 39-66. 
Fogelman, P. (2014). El cuerpo de la Virgen: discursos teológicos y representaciones históricas del cuerpo y la muerte de María. Revista Cultura\&Religión, 8(2), 197-231.

García, E. (1960). El Purén indómito como obra literaria. En Estudios de Lengua y Literatura como humanidades (pp. 82-104). Santiago: Imprenta Universitaria.

Glave, L. M. y Díaz, A. (2020). Clérigos y encomiendas en Tarapacá. Relaciones en la implantación del orden colonial durante el siglo XVI. Revista Cultura\&Religión, 14(2), 79-99.

Goic, C. (1988). Historia y crítica de la literatura hispanoamericana. Vol. 1. Barcelona: Crítica.

Góngora Marmolejo, A. ([1861] 1990). Historia de Chile desde su descubrimiento hasta el año 1575. Santiago: Ediciones de la Universidad de Chile.

Huidobro, M. G. (2017). El imaginario de la guerra de Arauco: mundo épico y tradición clásica. Santiago: Fondo de Cultura Económica.

Jaeger, W. (ed.). (2006). Paideia. Los ideales de la cultura griega. México: Fondo de Cultura Económica.

Johnston, P. (2016). Isn't it ironic? Euripides' deus ex machina in its literaryhistorical context. (Disertación doctoral). The University of Auckland, Auckland, Nueva Zelandia.

Lerner, I. (2002). Introducción. En A. de Ercilla, La Araucana (pp. 9-51). Madrid: Cátedra.

Louden, B. (2008). The gods in epic or the divine economy. En J. Miles Foley, A Companion to Ancient Epic (pp. 90-104). Oxford: Blackwell.

Mariño de Lobera, P. ([1595] 1960). Crónica del Reino de Chile. Madrid: Atlas.

Martínez, N. (2000). Las crónicas hispanas y las voces del otro. En J. L. Martínez (ed.), Los discursos sobre los otros. Una aproximación metodológica interdisciplinaria (pp. 25-61). Santiago: LOM.

Huidobro, M. (2021). Milagros e intervenciones divinas en la poesía épica sobre la guerra de Arauco en el siglo XVI. Revista Cultura y Religión, 15(2), 39-66. 
Mata, C. (2015). Episodios sobrenaturales en textos coloniales chilenos: el ‘aguacero santo soberano' en el poema Las Guerras de Chile (cantos X y XI). Romance notes, 55, 63-72.

Mignolo, W. (1992). La cuestión de la letra en la legitimación de la conquista. En K. Kohut (ed.), De conquistadores y conquistados. Realidad, representación, justificación (pp. 97-112). Frankfurt: Vervuert Verlag.

Oña, P. ([1596] 1917). Arauco domado. Santiago: Academia Chilena.

Ovalle, A. de. (ed. 2003). Histórica relación del Reino de Chile. Santiago: Pehuén Editores.

Piñero Ramírez, P. (1984). La épica hispanoamericana colonial. En L. I. Madrigal (coord.), Historia de la literatura hispanoamericana (pp. 161188). Madrid: Cátedra.

Prieto, A. (2001). Un estraño caso milagroso: la aparición de la Virgen en los textos tempranos de la conquista de Chile. Taller de Letras, (29), Pontificia Universidad Católica de Chile, 207-215.

Quesada, C. (2008). Épica religiosa hispanoamericana: La Cristiada de Diego de Hojeda y la máquina sobrenatural. En T. Barrera (ed.), Herencia cultural de España en América: siglos XVII y XVIII (pp. 255-276). Madrid: Iberoamericana-Vervuert.

Rodríguez, M. (2000). Un juego de ajedrez mal entablado: las estrategias del poder en Purén indómito. Acta Literaria, (25), 101-121.

Rodríguez, C. y Saavedra, A. (2008). Cosmovisión mapuche y manifestaciones funerarias. Un viaje entre lo etéreo y lo material”.Revista Cultura\&Religión, 2(3), 97-113.

Rosales, D. de. ([1674] 1877). Historia General del Reino de Chile: Flandes Indiano. Valparaíso: Imprenta del Mercurio.

Sanfuentes, O. (2008). Invenciones iconográficas en América. El caso de Santo Tomás y el de Santiago mata-indios. Diálogo Andino, (32), 45-58.

Sepúlveda, G. (1968). Retablo épico de La Araucana. Cuadernos Hispanoamericanos, 233, 440-453.

Huidobro, M. (2021). Milagros e intervenciones divinas en la poesía épica sobre la guerra de Arauco en el siglo XVI. Revista Cultura y Religión, 15(2), 39-66. 
Solomon, J. (2012). Boccaccio and the Ineffable, Aniconic God Demogorgon. International Journal of the Classical Tradition, 19(1), 31-62.

Triviños, G. y Rodríguez, M. (1996). La clausura de la epopeya en La Guerra de Chile. Estudios Filológicos, (31), 39-56.

Vivar, Gerónimo. ([1558] 1987). Crónica y relación copiosa y verdadera de los reinos de Chile. Santiago: Editorial Universitaria.

Weckmann, L. (1984). La herencia medieval de México. México: El Colegio de México.

Huidobro, M. (2021). Milagros e intervenciones divinas en la poesía épica sobre la guerra de Arauco en el siglo XVI. Revista Cultura y Religión, 15(2), 39-66. 